Supporting Information

\title{
A Direct Approach towards Label-Free DNA Detection by Surface-Enhanced Raman Spectroscopy: Discrimination of Single-Base Mutation in 50 Base-Paired Double Helixes
}

\author{
Yang Li, ${ }^{\text {a }}$ Tianyang Gao, ${ }^{\text {a }}$ Guantong Xu, ${ }^{\text {a }}$ Xiaoxuan Xiang ${ }^{\text {a }}$,Bing Zhao ${ }^{\text {a }}$ Xiaoxia Han, ${ }^{* a}$ and Xinhua \\ Guo*a,b.
}

\begin{abstract}
a State Key Laboratory of Supramolecular Structure and Materials, College of Chemistry, Jilin University, 2699 Qianjin Street, Changchun 130012, P. R. China.

${ }^{\mathrm{b}}$ Key Laboratory for Molecular Enzymology and Engineering of the Ministry of Education, College of Life Science, Jilin University, Changchun 130012, P.R. China
\end{abstract}

\section{Corresponding Author}

* Dr. Xinhua Guo. Tel: 86-431-89228949; Fax: 86-431-89228949;

E-mail: guoxh@jlu.edu.cn

* Dr. Xiaoxia Han. Tel: +86-431-85168473; Fax: +86-431-85193421;

E-mail: hanxiaoxia@jlu.edu.cn

\section{Content}

This Supporting Information provides the following information:

S-1. Title and author information

S-2. The experimental methods that are utilized in the paper.

S-3. Figure S1 and S2. CD spectra of all DNA strands studied in present work.

S-4. Figure S3 and S4. The SERS spectra of ssDNA and dsDNAs.

S-5. Figure S5. The SERS spectra of dsDNAs and Table S1.

S-6. The TEM spectrum of the Ag@DIANPs, Table S2 and Reference 


\section{EXPERIMENTAL METHODS}

\section{Materials}

DNA strands (HPLC grade) were purchased from Sangon Biotech (Shanghai) Co., Ltd. (Shanghai, China). All chemical reagents (Guaranteed reagent) are purchased from Sanbang Pharmaceutical Co., Ltd. (Changchun, China).

\section{Preparation of silver nanoparticles}

The synthesis of the silver sol is based on the Lee method. $0.036 \mathrm{~g}$ of silver nitrate, placed in a threenecked flask, was added with $200 \mathrm{ml}$ of water, and was heated to a slight boiling. Then $6 \mathrm{ml}$ of $1 \%$ sodium citrate solution was added to the reaction system to stop heating. The reaction is stopped until the solution turns from colourless to dark yellow and finally to green. Ultra-pure water was used throughout the experiment.

\section{Substrate pretreatment and Sample preparation}

The process diagram is shown in Scheme $1.5 \mathrm{~mL}$ of sodium citrate-reduced silver sol was centrifuged $\left(5000 \mathrm{rpm}, 15 \mathrm{~min}, 15^{\circ} \mathrm{C}\right)$, after the removal of the supernatant, $50 \mu \mathrm{L}$ of the centrifuged silver sol was mixed with $25 \mu \mathrm{L}$ of potassium iodide solution $(1 \mu \mathrm{M})$ at room temperature for 25 minutes. Then, $25 \mu \mathrm{L}$ of dichloromethane was added to the solution; as soon as the addition, the solution began to gradually divide into two layers. $50 \mu \mathrm{L}$ DNA sample was added to the mixture, followed by $20 \mu \mathrm{L}$ of $\mathrm{Al}^{3+}\left(0.01 \mathrm{M} \mathrm{Al}_{2}\left(\mathrm{SO}_{4}\right)_{3}\right)$, at this time, stratification would disappear. The prepared sample was shaken for SERS detection.

$1 \mathrm{~L} 0,1 \mathrm{HP} 3$ and DNA double helixes were made by heating the DNA strand in $50 \mathrm{mM} \mathrm{NH}_{4}^{+}$ buffer solution in water bath $\left(90^{\circ} \mathrm{C}\right)$ for 10 minutes following by a slowly cooling down step to room temperature in about 12 hours, then incubating in $4{ }^{\circ} \mathrm{C}$ for more than 4 days. Singlestranded DNA (ssDNA) and ultra-pure water was used throughout the experiment. The final concentration of all DNA helix structure and the ssDNA for SERS detection is about $1 \mu \mathrm{M}$ unless otherwise specified.

\section{SERS measurements}

SERS spectra were recorded on a LabRam Aramis Raman Microscope system (Horiba-Jobin Yvon) excited by $633 \mathrm{~nm}$ laser line. The samples were kept in capillaries before SERS measurements, and were excited by the laser through the capillary walls. The scan time is $10 \mathrm{~s}$, and each test is accumulated twice. All DNA sequences were $1 \mu \mathrm{M}$ in concentration throughout the SERS assay unless otherwise stated.

\section{CD spectroscopy}

CD spectra were recorded on a J-810 CD spectrometer (JASCO, Tokyo, Japan) using $0.2 \mathrm{~mm}$ path length Hellma cell at the room temperature. Spectra were recorded from 320 to $200 \mathrm{~nm}$ and presented as the averages of three scans. Each trace was measured at $100 \mathrm{~nm} / \mathrm{min}$ of scanning speed, with $2 \mathrm{~s}$ response time, $1 \mathrm{~nm}$ data pitch and $1 \mathrm{~nm}$ bandwidth. The background spectra corresponding to the buffer alone were subtracted from all DNA spectra. The final DNA concentration for CD detection is $25 \mu \mathrm{M}$. 


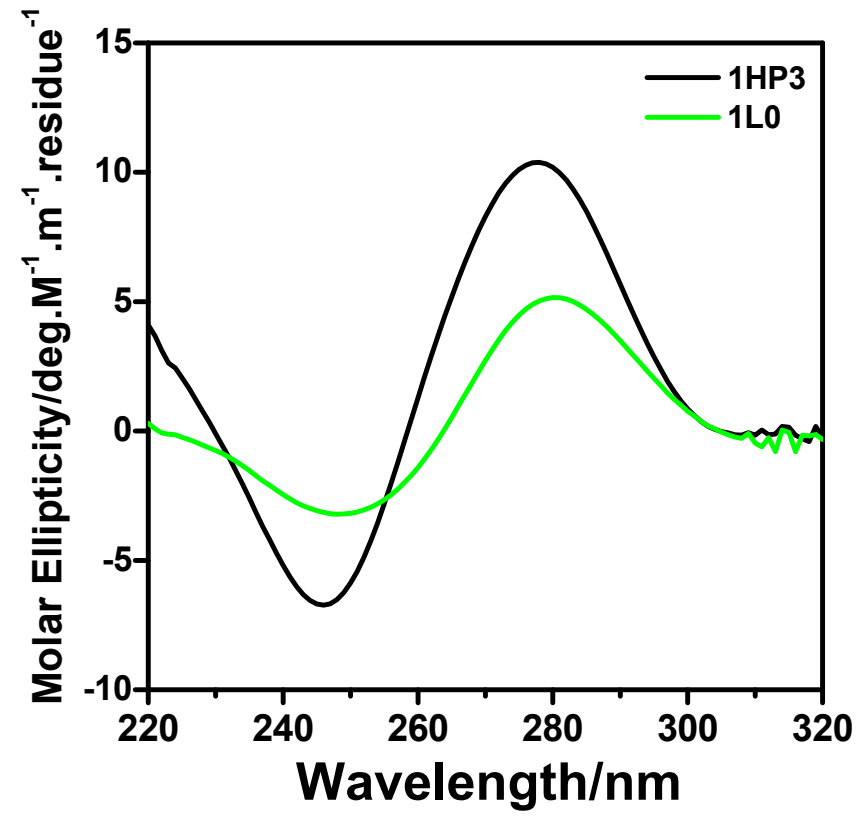

Figure S1 CD spectra of $1 \mathrm{HP} 3$ and $1 \mathrm{LO}$

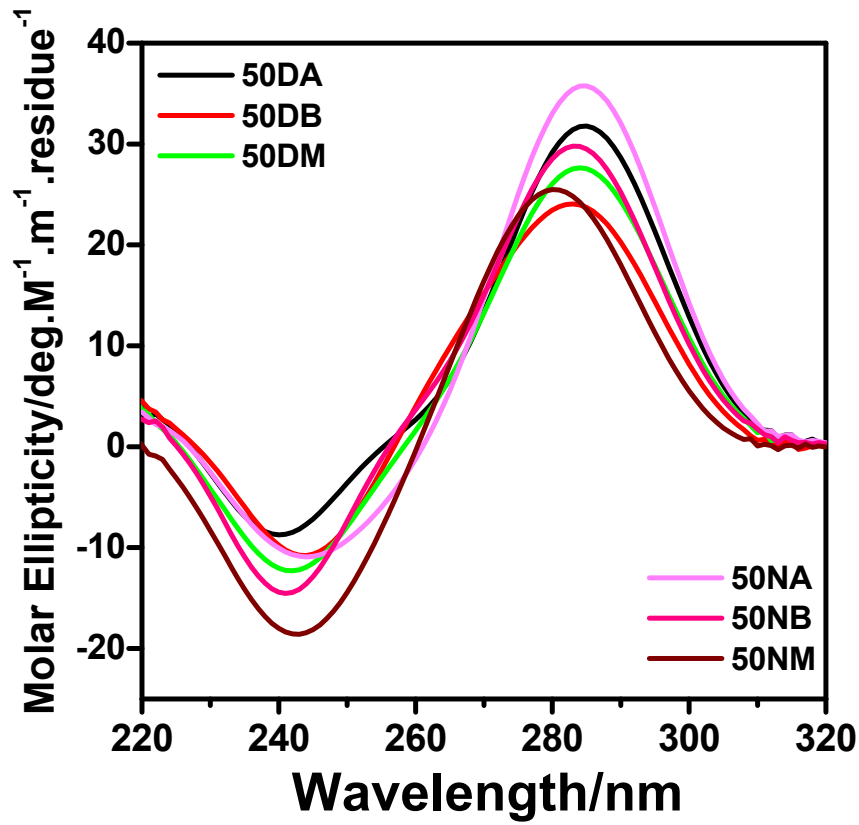

Figure S2 CD spectra of 50DA, 50DB, 50DM \& 50NA, 50NB , 50NM 


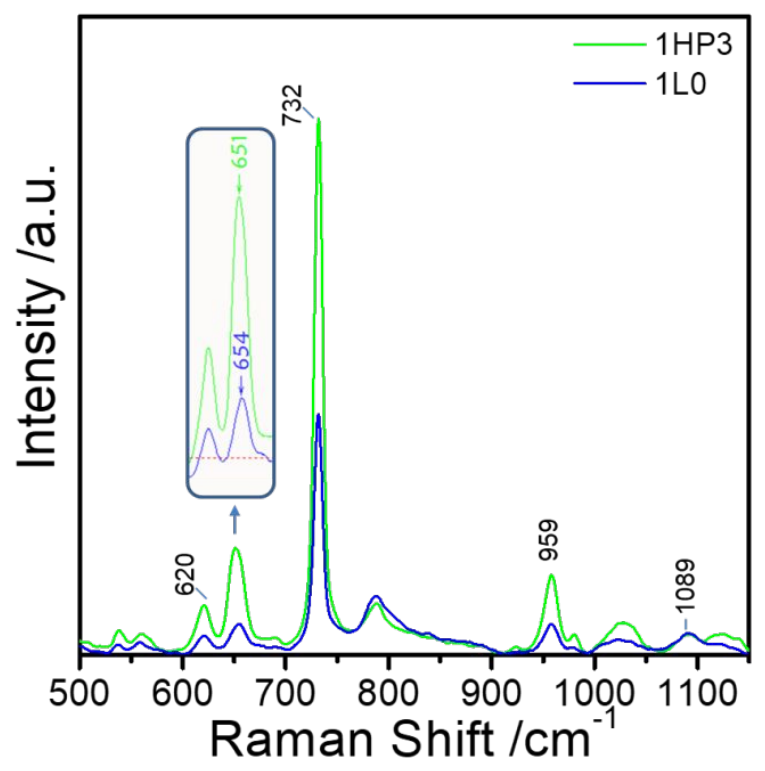

Figure S3. SERS spectra of 1HP3 (DNA hairpin) (green) and 1L0 (ssDNA) (blue) normalized by the intensity of the phosphate band at $1089 \mathrm{~cm}^{-1}$. The spectra were obtained by Ag@ IANPs as an SERS-active substrate.
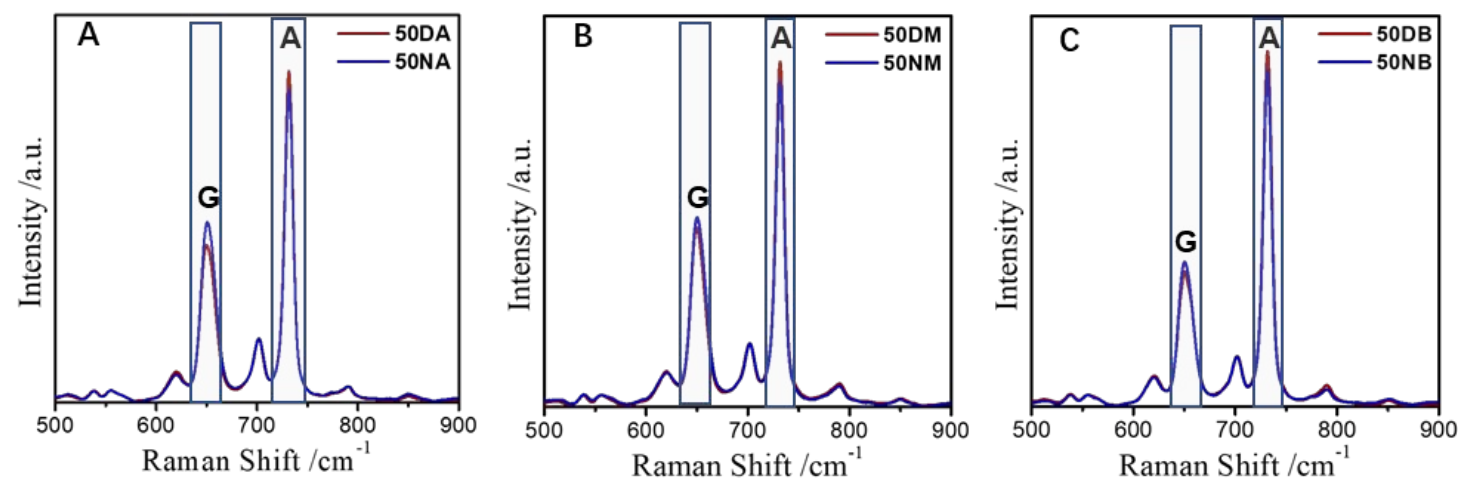

Figure S4. (A) SERS spectra of 50DA and 50NA. (B) SERS spectra of 50DM and 50NM. (C) SERS spectra of 50DB and 50NB. 

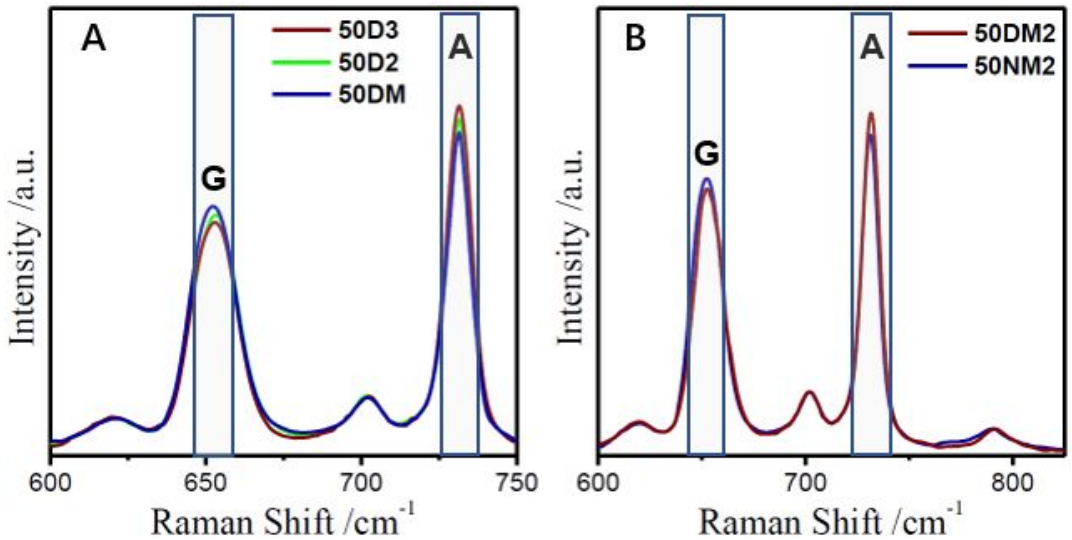

Figure S5. (A) SERS spectra of 50DM, 50D2 and 50D3. (B) SERS spectra of 50DM2 and 50NM2.

Table S1. SERS band assignments of the ssDNA and dsDNAs.

\begin{tabular}{|c|c|c|c|c|}
\hline \multicolumn{2}{|c|}{ Raman Shift $/ \mathrm{cm}^{-1}$} & \multicolumn{2}{|l|}{ Assignments } & \multirow[t]{2}{*}{ Refs. } \\
\hline & & ss DNA & dsDNA & \\
\hline 571 & 570 & $\mathrm{dG}$ ring br & dG C2'-endo/anti & {$[1,2,3]$} \\
\hline- & 620 & - & Loop & {$[2,3]$} \\
\hline 654 & 651 & dG R6 ring br & $\mathrm{dG}$ ring br, & {$[1,2]$} \\
\hline 732 & 732 & $\mathrm{dA}$ ring br & $\mathrm{dA}$ ring br & {$[2,3]$} \\
\hline 792 & 790 & $\mathrm{dT}$ ring br & $\mathrm{dT}$ ring br & {$[4]$} \\
\hline 794 & 790 & $\mathrm{dC}$ ring br & $v_{\mathrm{s}} \mathrm{OPO} ; \mathrm{dC}$ ring br & {$[4]$} \\
\hline 925 & 929 & $\mathrm{~d}$ & bk & {$[1,2,3]$} \\
\hline 951 & 955 & $\mathrm{~d}$ & $\mathrm{~d}, \mathrm{dG} \delta \mathrm{R} 5$ & {$[1,2,3,4]$} \\
\hline 1033 & 1031 & $\mathrm{~d}(v \mathrm{C}-\mathrm{O})$ & $\mathrm{d}(v \mathrm{C}-\mathrm{O})$ & {$[1,3,4]$} \\
\hline 1089 & 1089 & $v_{\mathrm{S}} \mathrm{PO}_{2}^{-}$ & $v_{\mathrm{s}} \mathrm{PO}_{2}^{-}, \mathrm{bk}$ & {$[1,2,3]$} \\
\hline 1184 & 1220 & dT & dT C2'-endo/anti & {$[1,3]$} \\
\hline 1251 & 1247 & $\mathrm{dT}, \mathrm{dG}$ & $\mathrm{dT}$, dG $\delta \mathrm{NH}(\mathrm{N} 2)$ & {$[3,4]$} \\
\hline 1374 & 1374 & - & $\mathrm{dG} \mathrm{C} 2$ '-endo/syn & {$[2,3]$} \\
\hline 1642 & 1647 & $\mathrm{dT}$ & $\mathrm{dT}, \mathrm{dC} \vee \mathrm{C} 5=\mathrm{C} 6$ & {$[2,3,4]$} \\
\hline 1689 & 1703 & $\mathrm{dG} v \mathrm{C}=\mathrm{O} \mathrm{H}$-bond to $\mathrm{H}_{2} \mathrm{O}$ & $\mathrm{dG} \vee \mathrm{C}=\mathrm{O}$ H-bond & {$[2,3]$} \\
\hline
\end{tabular}

Note: $\mathrm{d}=$ deoxyribose, $v=$ stretch, $\delta=$ deformation, $\mathrm{br}=$ breathing, $\mathrm{s}=$ symmetric, $\mathrm{s}=$ shoulder, $\mathrm{bk}=$ backbone. 


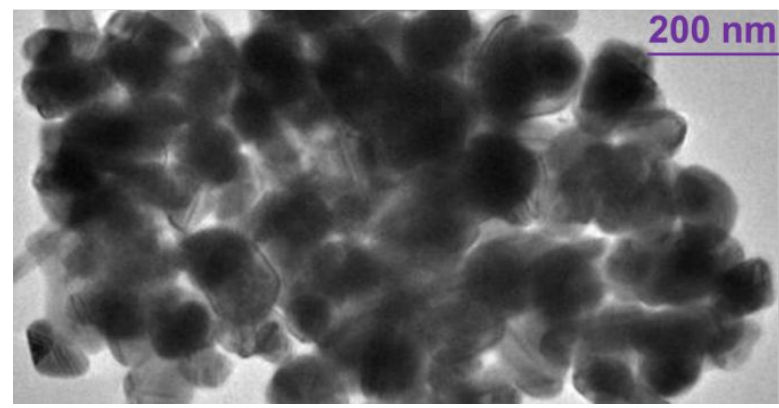

Figure S6. The TEM image of the of Ag DIANPs

Table S2. Sequences of the DNA strands additionally added in the study

\begin{tabular}{|c|c|}
\hline Name & $5^{\prime}-3$ \\
\hline \multirow[t]{2}{*}{$50 \mathrm{NM} 2$} & CTCAGGCCTCAGCTTCTCCGTGGGGTCCGTGTACAGCTGAGTGGTGGTGG \\
\hline & CCACCACCACTCAGCTGTACACGGACCCCACGGAGAAGCTGAGGCCTGAG \\
\hline \multirow[t]{2}{*}{ 50DM2 } & CTCAGGCCTCAGCTTCTCCGTGAGGTCCGTGTACAGCTGAGTGGTGGTGG \\
\hline & CCACCACCACTCAGCTGTACACGGACCTCACGGAGAAGCTGAGGCCTGAG \\
\hline \multirow[t]{2}{*}{$50 \mathrm{D} 2$} & CTCAGGCCTCAGCTTCTCCGTGTGGTCCGTGTACAGTTGAGTGGTGGTGG \\
\hline & CCACCACCACTC $\boldsymbol{A} \boldsymbol{A} \boldsymbol{C}$ TGTACACGGACCA $\boldsymbol{C} \boldsymbol{A} \boldsymbol{C G G A G A A G C T G A G G C C T G A G ~}$ \\
\hline \multirow[t]{2}{*}{$50 \mathrm{D} 3$} & CTCAGGCTTCAGCTTCTCCGTGTGGTCCGTGTACAGTTGAGTGGTGGTGG \\
\hline & CCACCACCACTC $\boldsymbol{A} \boldsymbol{A} \boldsymbol{C}$ TGTACACGGACCA $\boldsymbol{C} \boldsymbol{A} \boldsymbol{C G G A G A A G C T G} \boldsymbol{A} \boldsymbol{A} \boldsymbol{G C C T G A G}$ \\
\hline
\end{tabular}

\section{References}

1. Deng, H.; Bloomfield, V. A.; Benevides, J. M.; Thomas, G. J. Dependence of the Raman signature of genomic B-DNA on nucleotide base sequence. Biopolymers 1999, 50, 656-666.

2. Friedman, S. J.; Terentis, A. C. Friedman, S. J.; Terentis, A. C. Analysis of G-quadruplex conformations using Raman and polarized Raman spectroscopy. J. Raman Spectrosc. 2016, 47, 259268.

3. Krafft, C.; Benevides, J. M.; Jr, T. G. Secondary structure polymorphism in Oxytricha nova telomeric DNA. Nucleic Acids Res. 2002, 30, 3981-3991.

4. Papadopoulou, E.; Bell, S. E. J. Label-Free Detection of Single-Base Mismatches in DNA by Surface-Enhanced Raman Spectroscopy. Angew. Chem. 2011, 123, 9224-9227. 